POINCARÉ, Henry. La relativité de l'espace. In: L'année psychologique. 1906 vol. 13. pp. 1-17.

A presente tradução consiste numa importante crítica à noção de espaço geométrico por meio da noção de espaço restrito e expandido. Tal reflexão, no contexto da física quântica abre a reflexão para noções espaciais de duas até quatro dimensões. Apesar do texto ser direcionado para um público de geômetras, há nele passagens filosóficas com metáforas do sistema nervoso que permeiam o imaginário e as noções primitivas da realidade do espaço humano.

\title{
A RELATIVIDADE DO ESPAÇO
}

\section{I}

É impossível representar o espaço vazio; todos os nossos esforços para imaginar um espaço puro, de onde se excluiria a mudança de imagens de objetos materiais, não pode levar a uma representação onde as superfícies são fortemente coloridas, por exemplo, são substituições de linhas com baixa coloração e poderia ir até o fim desta forma, sem que tudo desvanecesse e levasse a nada. Isto é, de lá vem a relatividade irredutível do espaço.

Quem fala de espaço absoluto, emprega uma palavra sem sentido. Esta é uma verdade que foi proclamada há muito tempo por aqueles que têm pensado sobre isso, mas estamos muito frequentemente inclinados a esquecer.

Estou em um determinado ponto de Paris, Pantheon, por exemplo, e eu digo, vou voltar aqui amanhã. Se você me perguntar: Você quer dizer que você vai voltar para o mesmo ponto no espaço, estou tentado a responder: sim; e ainda tenho dito errado, porque amanhã a terra terá, levado consigo o Pantheon, numa distância que cobriu mais de 2 milhões de quilômetros. E, se eu queria esclarecer a minha expressão, então eu não ganharia nada, uma vez que nesses 2 milhões de quilômetros, nosso globo tem viajado em seu movimento pela relação original com o sol, o sol se move, por sua vez, em comparação com a Via Láctea, a Via Láctea em si é, provavelmente, em um movimento sem que possamos saber a sua velocidade. Então, nós ignoramos completamente o que jamais saberemos como o Pantheon se move em um dia. Em suma, eu queria dizer: Amanhã vou ver de novo a cúpula e o frontão do Pantheon, e, se não houvesse Pantheon, minha sentença não teria sentido e o espaço desapareceria.

Esta é uma das formas mais comuns do princípio da relatividade do espaço; mas há uma outra, em que Delboeuf ${ }^{1}$ particularmente insistiu. Suponhamos que, em uma noite,

\footnotetext{
${ }^{1}$ Filósofo e físico que estudou ilusões de ótica e as memórias do inconsciente.
} 
todas as dimensões do universo serão mil vezes maiores: o mundo continuará a ser semelhante a si mesmo, dando a similitude o mesmo sentido que o $3^{\circ}$ livro de geometria. Apenas, o que era um metro de comprimento agora medir um quilômetro, e o que foi ao longo de um milímetro de comprimento vai se tornar um metro. A cama onde eu dormia e meu próprio corpo serão ampliados na mesma proporção. Quando eu acordar na manhã seguinte, qual o sentimento que eu experimentarei na presença de uma transformação surpreendente? Bem, vou ver a mim mesmo como qualquer coisa. As medições mais precisas não serão capazes de me provar nada dessa imensa reviravolta, porque os metros que me serviram especificamente variaram na mesma proporção que os objetos que procuram medir.

Aqui há o direito de dizer, consequentemente, que sabemos qual é a distância entre dois pontos? Não, uma vez que esta distância pode sofrer enormes variações sem que percebamos, desde que as outras distâncias variaram nas mesmas proporções. Anteriormente, vimos que, quando eu digo que eu estarei aqui amanhã, isso não significa que eu vou estar amanhã no ponto no espaço onde estou hoje, mas vou estar amanhã à mesma distância do Pantheon hoje. E agora, esse enunciado não é suficiente e eu tenho que dizer: Amanhã e hoje, minha distância do Pantheon será igual para o mesmo número de vezes que a distância do meu corpo.

Mas isso não é tudo, eu assumi que as dimensões do mundo variaram, mas pelo menos neste mundo sempre foi assim mesmo. Podemos ir muito mais longe e uma das teorias mais surpreendentes da física moderna vai nos fornecer a oportunidade. De acordo com Lorentz e Fitzgerald, todos os corpos arrastados no movimento da terra sofrem deformação. Esta distorção é muito baixa, de fato, uma vez que todas as dimensões paralelas ao movimento da Terra cairiam de um cento milionésimos, enquanto dimensões perpendiculares a este movimento não iriam ser alteradas. Mas pouco importa que seja falível, apenas que ela existe pela conclusão de que estou prestes a tirar. E além disso, eu disse que era fraca, mas na realidade eu não sei nada do tudo; Eu mesmo era uma vítima da ilusão tenaz que nos fez acreditar que pensamos um espaço absoluto; Eu pensei sobre o movimento da Terra em sua órbita elíptica em torno do Sol, e eu admiti que a velocidade era de $30 \mathrm{~km}$ por hora. Mas sua verdadeira velocidade, eu não sei, eu não tenho nenhuma maneira de saber: pode ser 10 a 100 vezes maior, em seguida, a deformação será de 100, 10 000 vezes mais forte.

Podemos nos destacar em evidência dessa distorção? Não, obviamente; Aqui está um cubo que tem 1 metro quadrado; pelo movimento da terra, ele deforma-se, uma de suas 
bordas, que é paralela ao movimento, torna-se menor, as outras não variam. Se eu quero assegurar-me usando um medidor, eu meço as primeiras arestas perpendiculares ao movimento e as conclusões são que meu medidor é aplicado exatamente sobre essa vantagem; e, de fato, nem um nem o outro dos dois comprimentos é alterado, pois ambos são perpendiculares ao movimento. Quero medir depois a outra extremidade, que é paralela ao movimento; por isso que eu movo meu medidor e o transformo de modo a aplicá-lo sobre a minha vantagem. Mas o medidor mudou de direção, e tendo-se tornado paralelo ao movimento, por sua vez, sofreu deformação, de modo que a borda tem mais de um metro de comprimento, ele o aplicou exatamente, isso faz com que vá descrever qualquer coisa.

Em seguida, pergunto-me o que é o uso da hipótese de Lorentz e Fitzgerald se nenhum experimento pode permitir a verificação; é que a minha exposição estava incompleta; Falei apenas das medidas que podem ser feitas com um medidor; mas também se pode medir um período de tempo que a luz leva a atravessá-lo, desde que seja reconhecido que a velocidade da luz é constante e independente da administração. Lorentz poderia ter de fato assumindo que a velocidade da luz é maior na direção do movimento da Terra do que na direção perpendicular. Preferiu admitir que a velocidade é a mesma nestas várias direções, mas os corpos são menores em uma do que na outra. Se as superfícies de onda de luz tinham sofrido as mesmas deformações como corpos materiais, nós não percebemos o que seria a deformação de Lorentz-Fitzgerald ${ }^{2}$.

Em um caso como no outro, não pode haver questão de magnitude absoluta, mas a extensão dessa magnitude por meio de qualquer instrumento; este instrumento pode ser um contador, ou o caminho percorrido pela luz; é apenas a relação entre a quantidade do instrumento que medimos; e se esta relação é alterada, não temos nenhuma maneira de saber se é a grandeza ou o instrumento que tem variado. Mas o que eu vejo é que, nesta deformação do mundo não permanece semelhante a si mesma; as praças tornaram-se retângulos ou paralelogramos, círculos, elipses, esferas elipsóides. E ainda não temos nenhuma maneira de saber se essa deformação é real.

Obviamente que se pode ir muito mais longe: em vez que a deformação LorentzFitzgerald, cujas leis são particularmente simples, pode-se imaginar uma deformação bastante arbitrária. Os corpos podem ser deformados por leis arbitrárias, também complicando como nós as queremos, nós não devemos perceber o que todos os corpos fornecem, sem deformar a exceção seguindo as mesmas "leis". Dizendo todos os corpos

\footnotetext{
2 São os teóricos da física que precederam Einstein na descrição de como as medidas de espaço e tempo se alteram de acordo com as o referente e o sistema de medida.
} 
sem exceção, eu entendo, é claro, o nosso próprio corpo e os raios de luz que emanam dos vários objetos.

Se olharmos para o mundo de uma forma complexa desses espelhos que distorcem os objetos em uma maneira estranha, as relações mútuas das várias partes do mundo não serão alteradas; se, de fato, dois objetos reais se tocam, suas imagens também parecem se tocar. Na verdade, quando olhamos tal espelho, vemos grande parte da deformação, mas isso é porque existe o mundo real ao lado de sua imagem distorcida; e mesmo que este mundo real estivesse escondido, algo que não podemos esconder é a nós mesmos; podemos parar de ver ou pelo menos sentir, nossos corpos e nossos membros que não tenham sido distorcidos e continuamos a servir como instrumentos de medição. Mas se imaginarmos que o nosso corpo é deformado por si mesmo, e da mesma forma, se fosse visto no espelho, estes instrumentos de medição por sua vez irão ser dispensados e a deformação já não pode ser verificada.

Aqui os mesmos dois mundos que são a imagem um do outro; a cada objeto P no universo A corresponde no universo B um objeto P' que é a sua imagem; as coordenadas da imagem $\mathrm{P}^{\prime}$ são funções do objeto P especificado; Estas funções também podem ser bastante arbitrárias; Eu suponho que só temos as escolhida uma vez para todas. Entre a posição P e a de P ', existe uma relação constante; o que é essa relação não importa; ele só precisa ser constante.

Bem, estes dois universos serão indistinguíveis um do outro. Quer dizer, o primeiro será para os seus habitantes o que o segundo é para os seus. E seria assim tanto como os dois mundos permanecessem estranhos um ao outro. Suponha que vivemos no universo A, nós construímos nossa ciência e, particularmente, a nossa geometria; Enquanto isso, os habitantes do universo B tinham construído uma ciência, e como o seu mundo é a imagem da nossa, a sua geometria é também a imagem da nossa própria, ou melhor, ela vai ser a mesma. Mas se um dia nós abrirmos uma janela sobre o universo B, vamos ter pena. "Os infelizes, digamos assim, acreditam que têm uma geometria, mas o que eles chamam assim é uma imagem grotesca da nossa; suas linhas são todas as torcidas, seus círculos são corcundas, suas esferas têm desigualdades caprichosas". E nós não duvidaremos que eles dizem o mesmo de nós, e nós nunca vamos saber quem está certo.

Vemos em sentido amplo como deve ser entendida a relatividade do espaço; espaço é uma realidade amorfa e as coisas que estão no seu interior doam apenas uma forma. $\mathrm{O}$ que então devemos pensar desta intuição direta que nós faremos do direito ou da distância? Temos tão pouco a intuição da distância, em si, que, em uma noite, nós dissemos, uma 
distância poderia ser mil vezes maior sem sermos capazes de perceber se todas as outras distâncias tinham sofrido a mesma alteração. $\mathrm{E}$ até mesmo, uma noite do universo B poderia ser substituída para o universo A sem que tenhamos qualquer meio de saber, e então, as linhas retas de ontem teriam deixado de ser linhas retas e nós não devíamos perceber nada.

Parte do espaço não é, por si só e em sentido absoluto da palavra, igual a outra parte do espaço; pois se é para nós, não será para os habitantes do universo B; e eles só têm o direito de rejeitar nossa opinião que nós temos em condená-los.

Eu tenho mostrado em outros lugares, quais são as consequências desses fatos do ponto de vista da ideia de que temos de fazer uma geometria não-euclidiana e outras geometrias análogas; Eu não vou voltar mais; agora eu vou colocar uma visão um pouco diferente.

\section{II}

Se essa intuição de distância, direção, a linha reta, se essa intuição direta do espaço em uma palavra não existe mais, de onde vem a que nós cremos ter? Se esta é apenas uma ilusão, de onde se origina esta ilusão tão tenaz? Isto é o que deve ser analisado. Não há nenhuma intuição direta da grandeza, nós dissemos, e nós não podemos conseguir um relatório desta magnitude em nossos instrumentos de medição. Então, nós não poderíamos ter construído o espaço se tivéssemos tido um instrumento para medi-lo; Bem, esse instrumento, a que relatamos tudo o que usamos instintivamente, é o nosso próprio corpo. É em relação ao nosso corpo que nós localizamos objetos exteriores, e as únicas relações espaciais desses objetos que podem nos representar são as relações com o nosso corpo. É o nosso corpo, que serve, por assim dizer, do sistema de eixos coordenados.

Por exemplo, em um instante $\alpha$ foi dada a presença do objeto A, revelado a mim pelo sentido da visão; em outro instante $\beta$, a presença de um outro objeto B é revelado a mim por um outro sentido, o de ouvir ou tocar, por exemplo. Eu julgo que este objeto B ocupa o mesmo lugar que o objeto A. O que significa? Primeiramente, isso não significa que esses dois objetos ocupam, em dois momentos diferentes, um ponto de espaço absoluto, que, mesmo que isso existisse, escaparia ao nosso conhecimento, uma vez que, entre os tempos $\alpha$ e $\beta$, o sistema solar se mudou e não podemos saber o seu movimento. Isto significa dizer que esses dois objetos ocupam a mesma posição em relação com os nossos corpos relatados.

Mas mesmo isso, o que vai significar? As impressões que vieram a nós nesses objetos têm seguido absolutamente caminhos diferentes, o nervo óptico para o objeto A, o 
nervo acústico para o objeto B. Eles não têm nada em comum em termos qualitativos. As representações que podemos fazer desses dois objetos são absolutamente heterogêneas, irredutíveis aos outros. Só eu sei que, para alcançar o objeto A, eu só tenho que estender o braço direito de alguma forma, apesar de recusar-me a fazê-lo, eu represento as sensações musculares e sensações semelhantes que iriam acompanhar essa extensão, e esta representação está associada com a do objeto A.

Mas eu também sei que posso chegar ao objeto $B$, estendendo o braço direito da mesma forma, estendendo-o ao longo da mesma linha de sensações musculares. E quando eu digo que esses dois objetos ocupam a mesma posição, não vou dizer mais nada. Sei também que eu poderia ter alcançado o objeto por outro movimento apropriado do braço esquerdo e eu represento as sensações musculares que teriam acompanhado o movimento e o mesmo movimento do braço esquerdo acompanhado dos mesmos sentimentos, eu poderia ter alcançado o objeto B.

E isso é muito importante porque é assim que eu posso me defender contra os perigos que poderiam ou ameaçam o objeto A ou B. Em cada um dos choques que podem nos atacar, a natureza tem associado uma ou mais defesas que nos permitem preservar-nos. Uma mesma defesa pode atender a muitos choques; e, assim, por exemplo, o mesmo movimento do braço direito nos permita nos defender no instante $\alpha$ contra o objeto A e no instante $\beta$ contra o objeto $\mathrm{B}$. Da mesma forma, um único choque pode ser parado de várias maneiras, e nós dissemos, por exemplo, que você poderia chegar ao objeto A, ou por um movimento do braço direito ou por um movimento do braço esquerdo.

Todas estas defesas não têm nada em comum entre elas, caso contrário, elas permitem evitar um choque, e é isso, e isso por si só, que queremos dizer quando dizemos que estes são movimentos que levam ao mesmo ponto do espaço. Então, dizemos que esses objetos ocupam o mesmo ponto no espaço, não têm nada em comum, a não ser que a mesma parda possa permitir a defesa contra eles.

Ou, se preferir, imaginamos inumeráveis fios telegráficos centrípetos, outros centrífugas. O fio centrípeto alerta sobre acidentes que ocorrem fora, o fio centrífugo deve trazer o remédio. As conexões são feitas de tal forma que, quando um dos fios centrípetas está a levar a uma corrente, esta corrente se exerce em um relé ${ }^{3}$ e, portanto, faz com que uma corrente em um fio centrífuga, e as coisas estão organizadas para que vários fios centrípetas possam agir sobre o mesmo fio centrífuga, se o mesmo remédio combina com vários males; é porque um fio centrípeta pode dar movimento a vários fios centrífugas,

\footnotetext{
${ }^{3}$ N.T - É o termo técnico para a peça de distribuição elétrica de um circuito.
} 
quer simultaneamente ou de um do outro, sempre que um mesmo mal possa ser curado por diversos remédios.

Esse sistema complexo de associações é que a tabela de distribuição mostra como é toda a nossa geometria, ou, se quiser, todo a nossa geometria é instintiva. O que chamamos de nossa intuição da linha reta ou a distância, é a consciência que temos destas associações e seu caráter convincente.

E de onde vem esse caráter próprio e convincente é fácil de entender. Uma associação parece ainda mais indestrutível quanto mais antiga. Mas essas associações não são, para a maioria das conquistas do indivíduo, uma vez que vemos vestígios na criança que nasce; elas são conquistas da corrida. A seleção natural deve ter trazido estas mais rápido que todas as conquistas que foram mais necessárias.

A este ritmo, nós estamos falando sobre aqueles que tinham de ser os primeiros datados, já que sem eles a defesa do organismo teria sido impossível. Uma vez que as células já não eram meramente justapostas, e foram chamados a suportar uma ajuda mútua, era necessário organizar um mecanismo semelhante ao descrito acima para que esta ajuda fizesse não caminho errado e ir de encontro ao perigo.

Quando uma rã é decapitada, e uma gota de ácido é depositada num ponto sobre a pele, ela procura limpar o ácido com o pé mais próximo, e que se a perna é amputada, ela leva consigo a perna do lado oposto. Eis aí esta dupla defesa mencionada anteriormente, permitindo combater um mal por um segundo recurso, no caso de o primeiro falhar. E é esta multiplicidade de defesas, e da coordenação que ela resulta, que é o espaço.

Vemos quão profundo no inconsciente deve-se descer para encontrar os primeiros vestígios destas associações espaciais, uma vez que, as partes inferiores do sistema nervoso entram sozinhas no jogo. Como admirar, portanto, a resistência que se opõe a qualquer tentativa de dissociar o que esteve por tanto tempo associado? No entanto, é esta resistência que chamamos de evidência das verdades geométricas; Obviamente, isso não é nada mais do que a repugnância que sempre se sente em romper com hábitos muito antigos, que são sempre encontrados.

\section{III}

O espaço criado assim é apenas um pequeno espaço que não se estende para além do que meu braço pode alcançar; a intervenção de memória é necessária para regular os limites. Há pontos que permanecem fora do alcance, seja qual for o esforço que faço para estender a mão; se eu estava colado ao chão, como um exemplo de pólipo do mar que 
pode estender seus tentáculos, todos esses pontos estariam fora do espaço, uma vez que as sensações que podem experimentar a ação dos corpos que seriam colocadas lá, não estariam associadas com a ideia de qualquer movimento que nos permitisse chegar até eles, de alguma defesa adequada. Essas sensações não parecem ter qualquer carácter espacial e nós não tentamos localizá-las.

Mas nós não somos fixos ao solo, como os animais inferiores, podemos, se o inimigo estiver longe demais, andar até ele primeiro e estender a mão quando estamos perto o suficiente. É ainda uma defesa, mas uma defesa de longo alcance. Por outro lado, é uma defesa complexa, e na representação que nós nos fazemos entrar a representação de sensações musculares provocadas por movimentos das pernas, as sensações musculares causadas pelo movimento final do braço, os canais de sensação semicircular, etc. Não devemos nos representar como um complexo de sensações simultâneas, mas como um complexo de sensações sucessivas, seguindo uma à outra em uma ordem específica, e é por isso que eu disse antes que a intervenção da memória é necessária.

Observamos ainda que por ir à um mesmo ponto, posso me aproximar mais perto do objetivo, por ter menos que estender a mão; o que digo ainda? Essa não é mais que uma, mas são mil defesas que podem opor-se no mesmo perigo. Todos esses desvios são formados de sensações que podem não ter nada em comum, e ainda considerá-los como definindo o mesmo ponto no espaço, porque elas podem responder ao mesmo perigo e porque são umas e outras associadas com a noção desse perigo. É a capacidade de combater um mesmo choque, o que faz com que a unidade das várias defesas, como é a oportunidade de ser defendida da mesma forma que a unidade de defesas de choques de natureza tão diversa que podem ameaçar o mesmo ponto no espaço. É esta dupla unidade que faz a individualidade de cada ponto no espaço, e a noção de ponto não é outra coisa aqui.

O espaço que eu planejei no parágrafo anterior e que eu poderia chamar de espaço restrito foi relatado para coordenar eixos associados com meu corpo; esses eixos são fixos, porque meu corpo não se moveu e unicamente meus membros foram movidos. Quais são os eixos que se relacionam naturalmente como espaço estendidos, isto é o novo espaço que acabo de definir? Nós definimos um ponto pelo conjunto que precisa ser feito para conseguir alguma posição inicial do movimento do corpo. Os eixos são relacionados aos lugares da posição inicial do corpo.

Mas a posição que eu chamo inicial pode ser selecionada arbitrariamente de todas as posições que meu corpo tem ocupado sucessivamente; se a memória mais ou menos 
inconsciente destas posições sucessivas é necessária para a gênese do conceito de espaço, esta memória pode ser rastreada mais ou menos dentro do passado. Daí resulta que na definição do mesmo espaço há uma certa indeterminação, e é esta indeterminação que constitui a sua relatividade.

Não há mais espaço absoluto, só há espaço em relação a uma determinada posição inicial do corpo. Para um ser consciente que estaria ligado ao solo como os animais inferiores, e, portanto, saberia que o espaço é limitado, o espaço ainda é relativo (porque se relaciona com o seu corpo), mas este ser não o teria a consciência desta relatividade, porque os eixos que o trazem a este espaço limitado não iriam mudar! Sem dúvida, o rochedo em que isso seria coordenado não seria imóvel porque ele iria ser arrastado pelo movimento de nosso planeta; para nós, portanto, estes eixos mudariam a cada instante; mas, para o eixo, não iria mudar. Nós temos a capacidade de relatar o nosso espaço expandido agora para a posição A do nosso corpo, considerado como inicial, por vezes, tanto para a posição B, que teve por alguns instantes e nós somos livres para observar em seu entorno como inicial; a cada momento nós fazemos as mudanças inconscientes das coordenadas. Esta faculdade iria falhar o nosso ser imaginário que falta ter viajado acreditando no espaço absoluto. A cada instante o seu sistema de eixos lhe teria sido imposto; este sistema seria realmente seria bom em mudar a realidade, ele ainda seria o mesmo, uma vez que ainda seria o sistema único. Não é o mesmo para nós que a cada momento, temos múltiplos sistemas, entre os quais podemos escolher à vontade com a condição de volta pela memória mais ou menos distante do passado.

Isso não é tudo, o espaço limitado ou restrito não é homogêneo; os vários pontos deste espaço não podiam ser considerados como equivalentes, uma vez que tanto poderiam ser alcançados apenas por maiores esforços, enquanto outros seriam fáceis. Em vez disso, o nosso espaço prolongado nos aparece homogêneo, e nós dizemos que todos os pontos são equivalentes. O que isso significa?

Se começarmos a partir de uma posição A, podemos a partir desta posição para realizar certos movimentos $\mathrm{M}$, caracterizada por uma certa complexidade de sensações musculares. Mas a partir de outra posição B, podemos executar movimentos M' que será caracterizado pelas mesmas sensações musculares. Vamos, em seguida, a situação $a$ de um determinado ponto do corpo, desde a ponta do dedo indicador da mão direita, por exemplo, na posição inicial $\mathrm{A}$, ao seguir a situação $b$ do mesmo índice que, a partir desta posição A, executamos os movimentos $\mathrm{M}$. Em seguida, uma situação $a^{\prime}$ deste índice de posição B, e sua situação $b^{\prime}$ quando, a partir da posição B, executamos o movimento $\mathrm{M}^{\prime}$. 
Bem, eu costumava dizer que os pontos espaciais $a$ e $b$ são uns aos outros como os pontos $a^{\prime}$ e $b^{\prime}$ e significam simplesmente que as duas séries de movimentos M e $M$ 'são acompanhadas pelas mesmas sensações muscular. E como estou ciente de que, indo da posição A para a posição B, meu corpo era capaz de realizar os mesmos movimentos, eu sei que há um ponto no espaço que é o ponto de um $a^{\prime}$, este que qualquer ponto $b$ é no ponto $a$ de um modo que os dois pontos $a$ e $a^{\prime}$ são equivalentes. Isto é o que se chama a homogeneidade do espaço. Ao mesmo tempo, é por isso que o espaço é relativo, uma vez que as suas propriedades permanecem as mesmas, no que se refere aos eixos $\mathrm{A}$, ou eixos B. Assim que a relatividade do espaço e homogeneidade são uma e a mesma.

Agora, se eu quiser passar ao grande espaço, que já não é só para mim, mas onde eu possa acomodar o universo, eu vou ter que ficar por um ato de imaginação. Eu imaginarei que há uma sensação gigante que poderia alcançar os planetas em qualquer passo; ou, se preferir, o que eu sentirei a mim mesmo na presença de um mundo em miniatura, onde estes planetas seriam substituídos por pequenas bolas, enquanto que em uma dessas pequenas bolas que agitam em um lugar imaginário que chamaria de Eu. Mas este ato de imaginação seria impossível para mim, se eu não tivesse previamente construído meu espaço restrito e meu espaço alargado para meu uso pessoal.

\section{IV}

Por que todos estes espaços mantêm três dimensões? Vamos consultar o "quadro de disposição" de que falamos anteriormente. Temos de um lado, a lista dos diferentes perigos possíveis denotados por Al, A2, etc.; e do outro lado, a lista dos diferentes remédios que vou chamar o mesmo B1, B2, etc. Nós temos um conjunto de conexões entre os pontos da primeira lista e os da segunda, de modo que, por exemplo, quando o alarme de perigo A 3 aciona, ele vai ou vai pôr em ação o relé correspondente a defesa B 4.

Como tinho falado dos fios centrípetas e centrífugas, temo que uma forma em que tudo isso não é uma comparação simples, mas uma descrição do sistema nervoso. Este não é mais o meu pensamento, por várias razões: em primeiro lugar, eu não me permitia expressar uma opinião sobre a estrutura do sistema nervoso que eu não sei, e aqueles que têm estudado toda a sua vida o fazem com prudência; em seguida, porque, apesar de minha incompetência, sinto que deste regime seria muito simplista; e, finalmente, porque, na minha lista de defesas, essa é uma figura muito complexa, que pode até mesmo, no caso de espaço expandido, como vimos acima, ser formado e seguido por vários movimentos de 
braço. Assim, não há conexão física entre dois condutores reais, mas de associações psicológicas entre duas séries de sensações.

Se A 1 e A 2, por exemplo, são ambos associados com a defesa B 1, e A 1 também está associada com a defesa B 2, acontece geralmente que A 2 e B 2 também serão envolvidos. Se esta lei fundamental não era geralmente verdade, haveria uma imensa confusão e não haveria nada que poderia se assemelhar a um espaço de desenvolvimento ou a uma geometria. Como, de fato, temos definido um ponto no espaço? Fizemos isso de duas maneiras: em primeiro lugar é todos os alarmes A que estão em conexão com a mesma defesa B; É tudo sobre as outras defesas B que estão em conexão com o mesmo alarme A. Se a nossa lei não fosse verdade, deveríamos dizer que $\mathrm{Al}$ e A2 correspondem ao mesmo ponto que eles são todos os dois em ligação com B 1; mas também deve dizer ser que eles não correspondem ao mesmo ponto, desde que A 1 estaria em ligação com B 2 e que não seria o mesmo com o A 2. Esta seria uma contradição.

Mas, por outro lado, se a lei era estrita e sempre verdade, o espaço seria diferente do que é. Nós teríamos categorias entre as quais seriam distribuídas, em primeiro lugar, os alarmes Nas outras defesas B, bem definidas; estas categorias seriam excessivamente numerosas, mas elas são completamente separadas umas das outras. O espaço seria formado por diversos pontos, mas discretos, seria descontínuo. Não haveria razão para armazenar esses itens, em uma ordem, em vez de outra, nem, portanto, atribuir ao espaço três dimensões.

Mas não é assim; para sermos permitidos a ter um instante o entendimento da língua das pessoas que já conhecem a geometria; deve ser assim porque é a linguagem mais bem entendida por aqueles dos quais eu tento me fazer entender. Quando eu quero afastar o choque, eu tento chegar ao ponto onde se faz presente, mas eu só tenho que me aproximar perto o suficiente. Em seguida a defesa B 1, poderá responder a A 1 e A 2, se o ponto correspondente a $\mathrm{B} 1$ é suficientemente próximo do tempo da correspondente à $\mathrm{Al}$ e o que corresponde a uma A 2. Mas poderá se fazer o ponto que corresponde a outra defesa B 2, estar perto o suficiente para o ponto correspondente ao A l, e não ser o suficiente para o ponto correspondente a uma A 2. Por sorte que a defesa B2 se reunirá a A 1 incapaz de responder a $\mathrm{A} 2$.

Para aqueles que ainda não conhecem a geometria, ele simplesmente significa uma derrogação da lei mencionada acima. E então as coisas serão como se segue. Duas defesas B1 e B2 serão associadas com o mesmo A 1 avisado, e um grande número de avisos que vamos organizar na mesma categoria que A 1 e que irá coincidir com o mesmo ponto no 
espaço. Mas podemos encontrar avisos A 2 que serão associados com B2 sem ser em B 1, que, contudo, será B 3, que B3, não foi associada com A 1, e assim por diante, de modo que nós pode escrever a seguinte:

$$
\text { B1, Al, B2, A2, B3, A3, B4, A4, }
$$

em que cada termo está associado com o próximo e o precedente, mas não está mais separado das múltiplas fileiras.

É inútil dizer que cada um dos termos destes conjuntos não é isolado, mas parte de uma grande categoria de outros alarmes ou outros desvios que tem as mesmas conexões que ele, e podemos olhar como pertencente a um mesmo ponto no espaço. A Lei Básica, mas com exceções, permanece quase sempre, é verdade. Apenas como um resultado destas exceções, estas categorias, em vez de ser completamente separadas, parcialmente sobrepõem-se uma à outra e se interpenetram entre si, em certa medida, de modo que o espaço torna-se contínuo.

Por outro lado, a ordem na qual estas categorias devem ser providenciadas já não é arbitrária, se uma se refere ao resultado anterior, é claro que ele deve colocar entre A 1 e B 2 A 2 e, por conseguinte, entre B 1 e B 3 e não pode ser de molde colocar-se entre B 3 e B 4.

Aqui há então uma ordem na qual caem naturalmente nossas categorias que correspondem a pontos no espaço, e a experiência diz-nos que esta ordem vem sob a forma de uma entrada de tabela tripla, e é por isso que o espaço tem três dimensões.

\section{V}

Dessa forma, a propriedade característica do espaço é a de ter três dimensões, é uma propriedade do nosso quadro de distribuição, uma propriedade interna da inteligência humana, por assim dizer. Seria o suficiente para destruir algumas dessas conexões, ou seja, estas associações de ideias para um painel de distribuição diferente, e isso poderia ser suficiente para o espaço adquirir uma quarta dimensão.

Algumas pessoas se espantam com tal resultado. O mundo lá fora, pelo que pensam, devem muito bem ser algo por fazer. Se o número de dimensões vem da maneira como somos feitos, pode e tem os seres pensantes que vivem em nosso mundo, mas que seriam feitos a acreditar que o espaço tem mais ou menos de três dimensões. M. de Cyon não tem dito que os ratos japoneses, tendo apenas dois pares de canais semicirculares, acreditavam que o espaço tem duas dimensões? E então, este ser pensante, se ele é capaz de construir uma física, será que ele não é capaz de fazer uma física de duas ou quatro 
dimensões, e que em um sentido será a mesma que a nossa, uma vez que será a descrição do mesmo mundo em outro idioma?

Parece que de fato seria possível traduzir a nossa física na linguagem da geometria em quatro dimensões; tentar esta tradução seria ir para grandes comprimentos com pouco lucro, e eu só vou mencionar a mecânica de Hertz em que vemos algo semelhante. No entanto, parece que a tradução ainda seria menos simples do que o texto, e ainda que teria sempre a aparência de uma tradução, que a linguagem de três dimensões parece mais adequada para a descrição do nosso mundo, embora esta descrição possa ser feita ao rigor de outro idioma.

Além do que, não é por acaso que o nosso quadro foi formado. Há conexão entre o aviso e a parada A 1 B l, esta é uma propriedade interna de nossa inteligência; Mas por que essa conexão? É porque a defesa B 1 pode efetivamente defender contra o perigo A 1; e este é um fato externo para nós, é uma propriedade do mundo externo. Nosso quadro é, portanto, a tradução de um conjunto de fatos externos; se ele tem três dimensões, é porque ele se adaptou a um mundo que tinha certas propriedades; e o principal dessas propriedades é que existem sólidos naturais que estão seguindo substancialmente as leis que chamamos de lei do movimento de sólidos invariáveis. Se, portanto, a linguagem de três dimensões é uma das que mais facilmente descrevem o nosso mundo, não devemos nos surpreender; essa linguagem é modelada em nosso quadro; e isto é, a fim de viver neste mundo que esta tabela foi preparada.

Eu disse que nós poderíamos projetar, vivendo em nosso mundo, seres pensantes cuja distribuição da tabela é de quatro dimensões e, portanto, poderiam pensar no hiperespaço ${ }^{4}$. Não é certo, porém, que em tais seres, admitindo que nascem, vivem e que poderiam se defender contra os muitos perigos, que seriam então atacados.

\section{VI}

Algumas observações para terminar. Há um contraste marcante entre a grosseria dessa geometria primitiva, que se reduz ao que chamo de um quadro de distribuição, e a precisão infinita da geometria dos geômetras. E ainda assim nasceu disso; mas não só isso; ela teve que ser fertilizada pela faculdade que temos de construir conceitos matemáticos, como o Grupo por exemplo, e que estávamos procurando entre os conceitos puros o que melhor se adaptaria a este espaço áspero, o que tentei explicar é a gênese nas páginas anteriores do que é comum a nós como animais superiores.

\footnotetext{
${ }^{4}$ N.T - O hiperespaço, para a Física, é um espaço hipotético que contém quatro ou mais dimensões.
} 
A evidência de certos postulados geométricos não é, como dissemos, mais que a nossa relutância em desistir de hábitos muito antigos. Mas estes postulados são infinitamente precisos, enquanto esses hábitos têm algo essencialmente impreciso. Quando pensamos, temos muitos postulados infinitamente precisos, uma vez que esta é a única maneira de evitar a contradição; mas de todos os sistemas possíveis de postulados, é o que nesse que nos repugnamos a escolher, porque não concede o suficiente com os nossos hábitos; se turva, se eles são elásticos, eles têm um ponto de cedência.

Vemos que, se a geometria não é uma ciência experimental, é uma ciência nascida sobre a experiência, nós criamos o espaço que ela estuda, mas adaptando-se ao mundo em que vivemos. Nós escolhemos o espaço mais conveniente, mas a experiência tem guiado a nossa escolha; como a escolha estava inconsciente, parece que ganhamos; alguns dizem, que é a experiência necessária, outros que nascem com o nosso espaço de tudo; vemos que a partir das considerações acima, o que é nessas duas opiniões que há parte da verdade e do erro.

Nesta educação progressiva, que resultou na construção do espaço, que parte do indivíduo, e o que é a da raça, que é o que é difícil de determinar. Como um de nós, transportado desde o nascimento em um mundo completamente diferente, onde, por exemplo, dominar o corpo em movimento, de acordo com as leis do movimento de sólidos não-euclidianas, como, eu digo, poderia renunciar espaço ancestral para construir um espaço completamente novo?

A parte da raça parece predominante; No entanto, se é a ela que devemos o espaço áspero, impreciso, o espaço já referi anteriormente, o espaço dos animais superiores, não é na experiência inconsciente, individual, que devemos o espaço infinitamente preciso da geometria? Este é um problema difícil de resolver. No entanto, cita um fato que mostra que o espaço que nós herdamos de nossos ancestrais ainda mantém alguma plasticidade. Alguns caçadores aprender a atirar em peixes sob a água, embora a imagem do peixe é levantada por refração. Eles fazem de fato instintivamente: eles aprenderam a modificar o seu instinto antigo de direção; ou, se queremos substituir a associação A 1, B 1 por outra associação A 1, B 2, é porque a experiência tem mostrado a eles que a primeiro não teve êxito.

H. Poincaré. 